\title{
Risk factors for virological failure and subtherapeutic antiretroviral drug concentrations in HIV-positive adults treated in rural
} northwestern Uganda

\author{
Laurence Ahoua*1, Gunar Guenther ${ }^{1}$, Loretxu Pinoges ${ }^{1}$, Paul Anguzu ${ }^{2}$, Marie- \\ Laure Chaix ${ }^{3}$, Clotilde Le Tiec ${ }^{4}$, Suna Balkan ${ }^{5}$, David Olson ${ }^{5}$, Charles Olaro ${ }^{6}$ \\ and Mar Pujades-Rodríguez ${ }^{1,7}$
}

\author{
Address: ${ }^{1}$ HIV/AIDS Department, Epicentre, Paris, France, ${ }^{2}$ Medical Department, Médecins Sans Frontières, Arua, Uganda, ${ }^{3}$ Laboratory of Virology, \\ Paris Descartes University, Paris, France, ${ }^{4}$ Laboratory of Toxicology, Bicêtre Hospital, Kremlin Bicêtre, France, ${ }^{5}$ Medical Department, Médecins Sans \\ Frontières, Paris, France, ${ }^{6}$ Medical and Administrative Hospital Direction, Arua Regional Hospital, Arua, Uganda and ${ }^{7}$ International and \\ Environmental Health, Institute of Social and Preventive Medicine, Bern, Switzerland \\ Email: Laurence Ahoua* - laurence.ahoua@epicentre.msf.org; Gunar Guenther - gunarguenther@gmx.de; \\ Loretxu Pinoges - loretxu.pinoges@paris.msf.org; Paul Anguzu - msff-arua@paris.msf.org; Marie-Laure Chaix - marie-laure.chaix@nck.ap-hop- \\ paris.fr; Clotilde Le Tiec - clotilde.le-tiec@bct.ap-hop-paris.fr; Suna Balkan - suna.balkan@paris.msf.org; \\ David Olson - david.olson@ newyork.msf.org; Charles Olaro - olarocharles@yahoo.com; Mar Pujades- \\ Rodríguez - mar.pujades@epicentre.msf.org \\ * Corresponding author
}

Published: 3 June 2009

BMC Infectious Diseases 2009, 9:8I doi:10.1 |86/I47|-2334-9-8I
Received: 12 November 2008

Accepted: 3 June 2009

This article is available from: http://www.biomedcentral.com/I47I-2334/9/8 I

(C) 2009 Ahoua et al; licensee BioMed Central Ltd.

This is an Open Access article distributed under the terms of the Creative Commons Attribution License (http://creativecommons.org/licenses/by/2.0), which permits unrestricted use, distribution, and reproduction in any medium, provided the original work is properly cited.

\begin{abstract}
Background: Little is known about immunovirological treatment outcomes and adherence in HIV/AIDS patients on antiretroviral therapy (ART) treated using a simplified management approach in rural areas of developing countries, or about the main factors influencing those outcomes in clinical practice.

Methods: Cross-sectional immunovirological, pharmacological, and adherence outcomes were evaluated in all patients alive and on fixed-dose ART combinations for 24 months, and in a random sample of those treated for 12 months. Risk factors for virological failure $(>1,000$ copies $/ \mathrm{ml})$ and subtherapeutic antiretroviral (ARV) concentrations were investigated with multiple logistic regression.

Results: At I 2 and 24 months of ART, 72\% ( $n=70$ I) and 70\% ( $n=369)$ of patients, respectively, were alive and in care. About $8 \%$ and $38 \%$ of patients, respectively, were diagnosed with immunological failure; and $75 \%$ and $72 \%$ of patients, respectively, had undetectable HIV RNA ( $<400$ copies $/ \mathrm{ml})$. Risk factors for virological failure $(>1,000$ copies $/ \mathrm{ml})$ were poor adherence, tuberculosis diagnosed after ART initiation, subtherapeutic NNRTI concentrations, general clinical symptoms, and lower weight than at baseline. About $14 \%$ of patients had low ARV plasma concentrations. Digestive symptoms and poor adherence to $A R T$ were risk factors for low ARV plasma concentrations.

Conclusion: Efforts to improve both access to care and patient management to achieve better immunological and virological outcomes on ART are necessary to maximize the duration of first-line therapy.
\end{abstract}




\section{Background}

In 2007, approximately 810,000 adults were living with HIV/AIDS in Uganda, and 25-49\% of those requiring antiretroviral therapy (ART) were receiving treatment [1]. Studies conducted in urban areas of Uganda have shown good therapeutic outcomes in HIV-infected adults treated with ART [2-7]. However, little is known about immunovirological treatment outcomes, likelihood of achieving therapeutic plasmatic concentrations of antiretroviral (ARV) drugs, and adherence to treatment of patients treated using a simplified management approach [8] in rural areas of developing countries. Also, risk factors for virological failure have not been extensively investigated.

Rural programs face numerous challenges concerning HIV care and treatment in Africa, including lack of appropriate tools to diagnose common opportunistic infections and qualified human resources. The scale-up of ART in recent years has not necessarily been accompanied by an increased strengthening of health systems, and this disparity is likely to negatively affect the quality of care in HIV/ AIDS programs.

The main objective of this study was to describe clinical and immunovirological response to ART, patients' selfreported adherence, and plasma levels of ARV in HIVinfected adults who received free World Health Organization (WHO)-recommended ARV drug regimens as fixeddose combinations (FDCs) for 12 or 24 months in Arua, a rural area in northern Uganda. Furthermore, we investigated potential risk factors for virological failure and for subtherapeutic concentrations of non-nucleoside reverse transcriptase inhibitors (NNRTI) or protease inhibitors (PI).

\section{Methods \\ Study population}

Since 2002, Médecins Sans Frontières (MSF) in collaboration with the Ugandan Ministry of Health has provided ART free of charge in the regional referral hospital of Arua. The program initially served the whole West Nile region, but decentralization of patients on ART to other district and missionary hospitals was started in 2004. Eligibility criteria for ART are those recommended in the WHO guidelines for scaling up ART in resource-poor settings [9]. Patients are seen by nurses monthly or every 3 months for drug refills and to assess ARV drug toxicity; and by clinical officers every 2 or 6 months. CD4 T-cell counts are currently monitored at ART start (for patients with no WHO clinical stage 4 conditions) and every 6 months (yearly after the first year on ART since 2005). No routine viral load (VL) monitoring is performed.

Data routinely collected using standardized forms and entered into the FUCHIA software (Epicentre, Paris) were, at program inclusion, date of birth or age, and history of
ARV use; and at ART start, date, regimen, clinical WHO conditions diagnosed, weight, height, and CD4 T-cell counts. By November 2005, approximately 8,000 patients were followed in the program, $90 \%$ of them were adults, and $45 \%$ were alive and followed on ART.

\section{Study design}

Before the start of the study (November 2005), we identified patients included in two observational open cohorts of HIV-infected patients who initiated ART in the previous $12 \pm 2$ months (M12 cohort) and $24 \pm 2$ months (M24 cohort). Patients found to be alive and still on ART were eligible for participation in a cross-sectional survey if they were contacted within the study window period, were non-pregnant or breastfeeding at the time of the study, and provided written informed consent. The study sample size was calculated assuming that 16\% (M12) and 20\% (M24) of these patients, respectively, would have detectable VL $[10,11]$. Hence, we included all patients from the M24 cohort $(\mathrm{N}=369)$ and randomly selected 275 patients from the $\mathrm{M} 12$ cohort $(\mathrm{N}=701)$.

\section{Data collection and laboratory testing}

During the cross-sectional survey conducted between $28^{\text {th }}$ November 2005 and 2nd May 2006, we used a standardized questionnaire to collect information on diagnosed acute severe illnesses, ARV-related toxicity, anthropometric measurements, and adherence to treatment. Two selfreported indicators of adherence were calculated: the percentage of pills taken in the last 4 days (number of pills taken as a proportion of the total number of pills prescribed); and the percentage of reported adherence in the last 30 days using a 6-point visual analogue scale (30-day VAS). Good adherence was defined as a value $\geq 95 \%$ pills or a VAS score $>4$ [9].

Plasma concentrations of nevirapine (NVP), efavirenz (EFV), and nelfinavir (NFV) were determined by high-performance liquid chromatography $[12,13]$ on blood samples collected 12 hours after ingestion of the last dose of ARV. Hemoglobin, full blood cell count, alanine aminotransferase, and plasmatic creatinine concentrations were measured. CD4 T-cell counts were quantified using semi-automated (Cyflow counter, Partec, Münster, Germany) or manual (Dynabead, Dynal Biotech SA, Compiègne, France) techniques. HIV-1 RNA was quantified with the ANRS generic real-time PCR test [14]. Genotypic resistance tests were performed in plasma samples with HIV-1 RNA $\geq 1,000$ copies/ml using the consensus technique of the AC11 ANRS 2007 v16; possible resistance was considered as resistance $[15,16]$.

\section{Statistical analysis \\ Retrospective cohort analysis}

Probabilities of survival for all patients included in the two cohorts were estimated using Kaplan-Meier methods. 
Patients missing their last clinical appointment for 2 months or more were considered lost to follow-up (LTFU).

\section{Analysis of cross-sectional survey data}

Characteristics of patients, ARV toxicity, and adherence were described using standard statistics. Laboratory ARV toxicity was graded according to the 2004 AIDS Clinical Trials Group criteria [17]. We defined immunological failure as a CD4 T-cell measurement of $\leq 100 / \mathrm{mm}^{3}$ at 12 months, $\leq 200 / \mathrm{mm}^{3}$ at 24 months, or below the value recorded at ART start at 12 or 24 months of ART $[18,19]$. Virological failure was defined as the presence of $\geq 1,000$ HIV RNA copies/ml. Characteristics of patients at ART start and at the time of the survey, ARV toxicity, ARV plasma levels, and adherence were described using standard statistics.

Based on ARV therapeutic ranges, $(4,000-8,000 \mathrm{ng} / \mathrm{ml}$ for $\mathrm{NVP}, 1,000-4,000 \mathrm{ng} / \mathrm{ml}$ for EFV, and $1,000-4,000 \mathrm{ng} / \mathrm{ml}$ for NFV [20]), we defined 3 levels of plasma drug concentrations: low (below the lower therapeutic range limit), normal (within the therapeutic range), and high (above the higher therapeutic ranged limit).

We investigated predictive factors for virological failure (HIV-1 RNA $\geq 1,000$ copies/ml) and low plasma NVP, $\mathrm{EFV}$, or NFV concentrations using a multiple logistic regression analysis. The covariates studied were sex, age (15-34 vs. $\geq 35$ years), level of education (primary or no education vs. secondary or higher), ARV-experienced, WHO staging (1/2 vs. $3 / 4)$, tuberculosis (TB) diagnosis after ART initiation, baseline or nadir CD4 cell count $(<50$ vs. $\geq 50$ cells $/ \mathrm{mm}^{3}$ ), weight $\leq$ baseline, cohort (M12 vs. M24), presence of ARV-related toxicity, and poor adherence to ART (95\% vs. $\geq 95 \%)$. For each outcome, we applied a backwards elimination approach to an initial model including those covariates associated with the outcome in univariate analyses $(P<0.25)$. The goodness-offit $\chi^{2}$ test was used to assess the fit of the final models [21]. All analyses were performed in Stata 9.0 (Stata Corp., College Station, TX, USA).

The protocol was approved by the Uganda National Council for Science and Technology and the Ugandan AIDS Research Committee.

\section{Results}

\section{Retrospective cohort analysis}

By the end of the study (May 2006), 130 patients of the 1,523 patients included in the studied cohorts (48/967 of M12 and 82/556 of M24) had died, and 282 (187 of M12 and 95 of M24) had been lost-to-follow-up. Eighty-three percent of the 130 recorded deaths occurred during the first 6 months of ART. Probabilities of survival at 12 and 24 months of ART were 0.91 (95\% CI 0.89-0.92) and 0.88 (95\% CI 0.86-0.90), respectively, and probabilities of remaining in care were 0.76 (95\% CI $0.74-0.78)$ and 0.70 (95\% CI 0.67-0.72), respectively.

\section{Participants in the cross-sectional survey}

Of the 967 adults who initiated ART between September 2004 and July 2005 (M12 cohort), 701 (72\%) were still alive and on ART at the time of the start of the survey. Of the 556 adults who initiated ART between September 2003 and July 2004 (M24 cohort), 369 (66\%) were alive and on ART. A total of 229 ( $83 \%$ of eligible) M12 and 277 (75\% of eligible) M24 patients participated in the crosssectional survey. Reasons for exclusion were pregnancy or breastfeeding, inability to trace the patient, or a screening visit outside the study period ( $12 \pm 2$ or $24 \pm 2$ months of ART) (Figure 1). Men and patients ARV-experienced at ART start were more likely to be included in the study than women or ARV-naïve patients.

\section{Survey participant characteristics at ART start}

Study patients had been followed in the HIV program of Arua prior to ART initiation for a median time of 6 (M12) and 4 (M24) months, and 98\% were ARV-naïve. At ART initiation, median age was 37 years, $88 \%$ of patients were in WHO clinical stage 3 or 4 , and approximately $17 \%$ had a body mass index (BMI) $<17 \mathrm{~kg} / \mathrm{m}^{2}$ (Table 1 ). More than $25 \%$ had a CD 4 cell count $<50$ cells $/ \mathrm{mm}^{3}$, and most patients received stavudine/lamivudine/NVP (d4T/3TC/ NVP). Nine percent of patients had been diagnosed with TB.

\section{Patient characteristics at survey}

At the time of the survey, 10 patients were treated for active $\mathrm{TB}$, and $86 \%$ of patients remained on FDC $\mathrm{d} 4 \mathrm{~T} /$ 3TC/NVP. No patients were receiving second-line therapy. All participants reported at least one type of clinical intolerance, most frequently headache and digestive symptoms such as epigastric/abdominal pain or meteorism. Peripheral polyneuropathy and dermatologic disorders were reported in more than $30 \%$ of patients in both cohorts. Forty percent of patients had at least one moderate or mild abnormal laboratory result. Seven patients had grade 3 or 4 abnormal laboratory results, 6 had grade 3 neutropenia (3 M12 and $3 \mathrm{M} 24$ ), and 1 (M24) grade 4 anemia.

\section{Treatment adherence}

In the M12 cohort, good adherence to ART, defined as all pills taken in the last 4 days, was reported by 200 (87.3\%) patients (or by 198 [86.5\%] patients when the 30-day VAS 

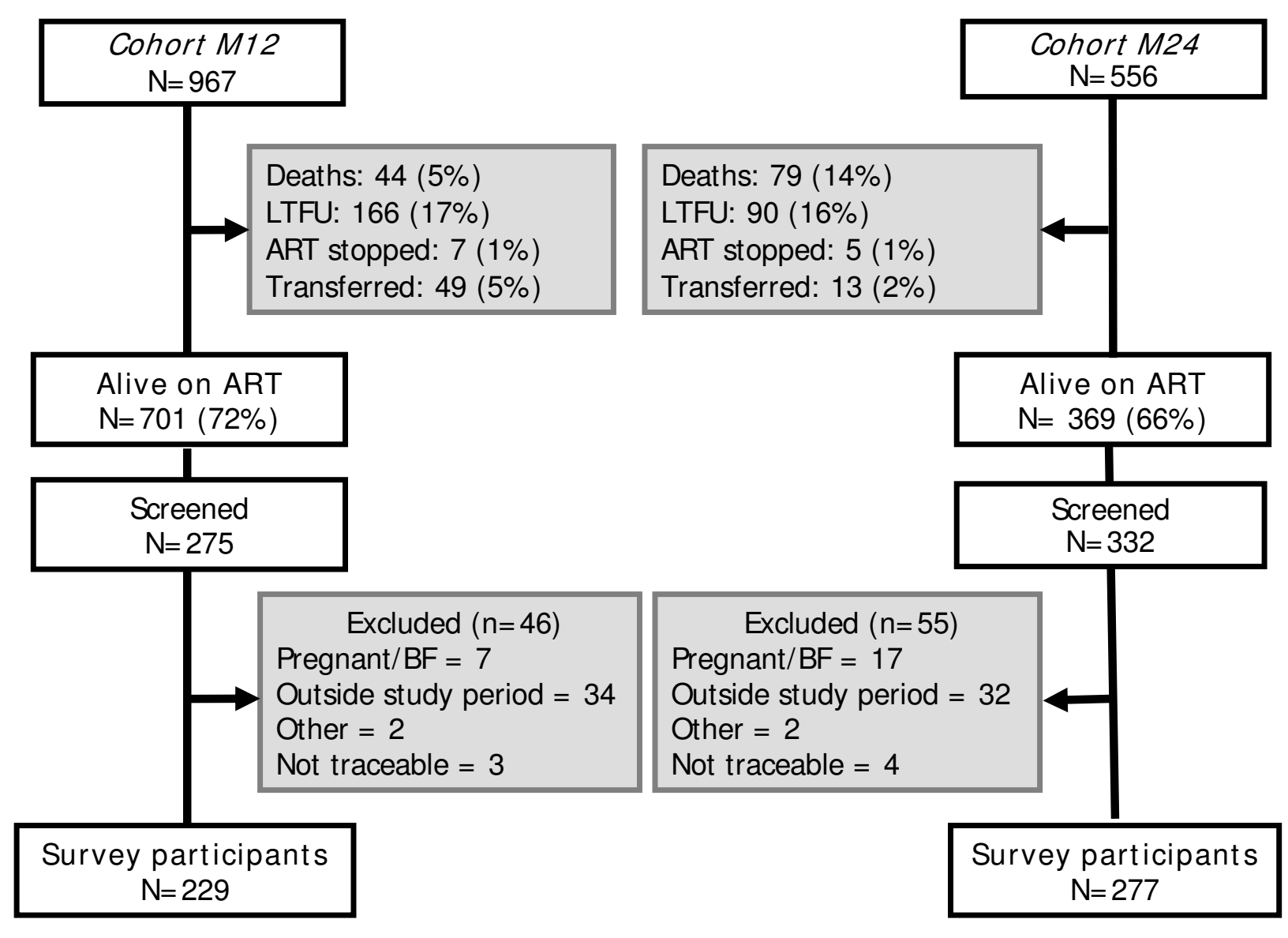

\section{LTFU, lost to follow-up; ART, antiretroviral therapy; BF, breastfeeding}

Figure I

Patient cohort profiles at study start (November 2005).

was used). In the M24 cohort, good adherence to ART in the last 4 days was reported by 258 (93.1\%) patients (250 [90.3\%] using VAS) (Table 1).

Overall, the two measures of adherence were moderately correlated (Pearson's coefficient 0.48 ) and correlation was stronger for M12 than for M24 measurements (0.59 and 0.35 , respectively). Twenty-seven $(6.0 \%)$ patients considered as having good adherence by VAS reported to have forgotten taking one or more pills in the last 4 days; while $37(8.1 \%)$ of those considered as having good adherence through 4-day recall reported poor adherence with VAS. A total of $85(16.8 \%)$ patients were categorized as poorly adherent to ART by any of the two methods.

\section{Immunological and virological failure}

At M12, median CD4 cell count was 223 cell $/ \mathrm{mm}^{3}$, immunological failure was diagnosed in $7.9 \%$ of patients, and $40 \%$ had $<200$ cells $/ \mathrm{mm}^{3}$ (Table 1 ). Furthermore, $75 \%(171 / 229)$ of patients had undetectable HIV RNA (<400 copies/ml), and 89.1\% (204/229) had <1,000 HIV RNA copies/ml.

At M24, median CD4 cell count was 238 cells $/ \mathrm{mm}^{3}$, immunological failure was diagnosed in $38 \%$ of patients, and $36 \%$ of patients had $<200$ cells $/ \mathrm{mm}^{3}$. Seventy-two percent of patients $(198 / 277)$ had HIV viral suppression, and $81.9 \%(227 / 277)$ had $<1,000$ HIV RNA copies/ml. 
Table I: Patient characteristics and outcomes

\begin{tabular}{|c|c|c|}
\hline Patient characteristics & $\begin{array}{r}\text { Cohort MI2 } \\
(\mathbf{N}=229)\end{array}$ & $\begin{array}{r}\text { Cohort M24 } \\
(\mathrm{N}=277)\end{array}$ \\
\hline \multicolumn{3}{|l|}{ Characteristics at ART start } \\
\hline Women (\%) & $15 \mid(65.9)$ & $173(62.4)$ \\
\hline Median age, years [IQR] & $36.8[32.0-42.3]$ & $36.5[30.8-42.6]$ \\
\hline ARV naïve (\%)* & $225(98.2)$ & $273(98.6)$ \\
\hline Median follow-up before ART, months [IQR] & $6.2[3.9-11.4]$ & $3.7[1.8-7.7]$ \\
\hline First ART regimen prescribed d4T/3TC/NVP & $226(98.7)$ & $265(95.7)$ \\
\hline WHO stage 3 or $4(\%)$ & $20 \mathrm{I}(87.7)$ & $246(88.8)$ \\
\hline Body mass index $<17$ kg/m² $(\%)$ & $38(17.8) ; n=214$ & $43(16.8) ; n=256$ \\
\hline CD4 cell count, cells $/ \mathrm{mm}^{3}$ & $n=133$ & $n=239$ \\
\hline Median $[\mathrm{IQR}]$ & $100[45-147]$ & $93[40-144]$ \\
\hline$<50(\%)$ & $36(27.1)$ & $73(30.5)$ \\
\hline \multicolumn{3}{|l|}{ Characteristics at time of survey } \\
\hline Non-cumulative WHO stage at survey (\%) & $\mathrm{n}=223$ & $\mathrm{n}=267$ \\
\hline Asymptomatic & $136(6 \mid .0)$ & $160(59.9)$ \\
\hline Stage 1 or 2 & $63(28.2)$ & $86(32.2)$ \\
\hline Stage 3 or 4 & $24(10.8)$ & $21(7.9)$ \\
\hline \multicolumn{3}{|l|}{ Body mass index, $\mathrm{kg} / \mathrm{m}^{2}$} \\
\hline Median [IQR] & $20.4[18.9-22.0]$ & $20.8[19.0-22.5]$ \\
\hline$<18.5 \mathrm{~kg} / \mathrm{m} 2(\%)$ & $43(18.8)$ & $52(18.7)$ \\
\hline Median weight gain since ART start, kg [IQR] & $3[1-6]$ & $2[0-7]$ \\
\hline \multicolumn{3}{|l|}{ ARV-clinical related symptoms (\%) } \\
\hline Asthenia & $70(30.7)$ & $84(30.3)$ \\
\hline Digestive disorders & $132(57.6)$ & $146(52.7)$ \\
\hline Neurological disorders & $102(44.5)$ & III (40.1) \\
\hline Dermatological disorders & $70(30.6)$ & $84(30.3)$ \\
\hline Morphological disorders & $39(17.0)$ & $72(26.0)$ \\
\hline \multicolumn{3}{|l|}{ CD4 cell count, cells $/ \mathrm{mm}^{3}$} \\
\hline Median [IQR] & $223[163-308]$ & $238[|72-32|]$ \\
\hline$<200(\%)$ & $92(40.2)$ & $100(36.1)$ \\
\hline Median gain since ART start [IQR] & $+115[59-170]$ & $+139[75-215]$ \\
\hline \multicolumn{3}{|l|}{ Pills taken in last 4 days (\%) } \\
\hline Good adherence & $200(87.3)$ & $258(93.1)$ \\
\hline Poor adherence & $29(12.6)$ & $19(6.9)$ \\
\hline \multicolumn{3}{|l|}{ 30-day VAS (\%) } \\
\hline Good adherence & $198(86.5)$ & $250(90.3)$ \\
\hline Poor adherence & $31(13.5)$ & $27(9.7)$ \\
\hline Plasmatic NVP level (\%) & $\mathrm{n}=204$ & $\mathrm{n}=258$ \\
\hline Low & $39(19.1)$ & $32(12.4)$ \\
\hline Normal & $115(56.4)$ & $172(66.7)$ \\
\hline High & $50(24.5)$ & $54(20.9)$ \\
\hline Plasmatic EFV level (\%) & $n=23$ & $n=18$ \\
\hline Low & I (4.4) & - \\
\hline Normal & $13(56.5)$ & $11(61.1)$ \\
\hline High & $9(39.1)$ & 7 (38.9) \\
\hline
\end{tabular}

VAS, visual analogue scale; IQR, interquartile range

*ARV-naïve does not include women who received PMTCT prophylaxis.

\section{Frequency of drug-resistant viruses}

We performed genotypic tests for $62(82.7 \%)$ of patients with VL $\geq 1,000$ copies/ml (PCR amplification failed for 13 samples) (Table 2$)$. Five patients ( $8 \%$ ) had no mutations. Wild-type viruses were found in 16 (26\%; 6 at M12 and 10 at M24) patients. Fourteen (70\%) patients at M12 and $32(76 \%)$ at M24 had $\geq 1$ mutation conferring drug resistance to NRTIs or NNRTIs. The overall frequency of resistant virus among treated patients was $7.3 \%(14 / 191)$ at M12 and 13.3\% (32/240) at M24 (excluding 62 
Table 2: Results of virological and genotypic resistance testing by cohort

\begin{tabular}{lrr}
\hline & Cohort MI2 & Cohort M24 \\
\hline HIV RNA $\geq$ I,000 copies/ml (\%) & 25 & 50 \\
\hline Available genotypic resistance (\%) & $20(80.0)$ & $42(84.0)$ \\
\hline Wild-type virus (\%) & $6(30.0)$ & $10(23.8)$ \\
Resistance to $\geq$ I ARV drug (\%) & $14(70.0)$ & $32(76.2)$ \\
Resistance to EFV and NVP (\%) & $3(15.0)$ & I (2.4) \\
Resistance to 3TC, EFV, and NVP (\%) & $9(45.0)$ & $22(52.4)$ \\
Extensive resistance* (\%) & $2(10.0)$ & $9(21.4)$ \\
\hline
\end{tabular}

$A R V$, antiretroviral; EFV, efavirenz; NVP, nevirapine; 3TC, lamivudine

*Resistance to EFV, NVP, 3TC, stavudine, zidovudine, or tenofovir, and didanosine, or multidrug resistance.

patients with VL $=400-999$ and 13 with failing amplification reaction); or $18.8 \%$ (43/229 and 52/277, respectively) if the 75 excluded patients were assumed to have resistance mutations.

The most prevalent NRTI and NNRTI mutations were $\mathrm{M} 184 \mathrm{~V}$ and $\mathrm{K} 103 \mathrm{~N}$, respectively. In the M12 cohort, 3 viruses were resistant to EFV and NVP, and 9 to both 3TC and NNRTIs (EFV and NVP). One virus was resistant to 3TC, d4T, zidovudine (AZT), and NNRTIs (EFV and NVP), and 1 harbored K65R, K103N, Y181C, and G190A mutations conferring resistance to tenofovir (TDF), EFV, NVP, and possibly didanosine (ddI).

In the M24 cohort, only 1 virus was resistant to NVP and EFV, and 22 to both 3TC and NNRTIs. Six viruses with resistance mutations to both 3TC and NVP had additional resistance to $\mathrm{d} 4 \mathrm{~T}$ and/or AZT. Three viruses harbored a K65R mutation conferring resistance to TDF and possibly to ddI. One virus had a multidrug resistance profile (K65R, T69A, V75I, K103N, F116Y, Q151M, V179S, $\mathrm{Y} 181 \mathrm{C}$, and $\mathrm{M} 184 \mathrm{~V})$, conferring resistance to all the NRTIs and to EFV and NVP.

Thymidine analogue mutations (TAMs) conferring resistance to AZT and d4T were observed in 5\% and $14 \%$ patients at M24, respectively. Resistance to both TDF and ddI were described in 5\% (1/20) at M12 and 7\% (3/42) at M24. The NRTI multidrug resistance complex (Q151M) was found in 1 patient at M24. None of the viruses had mutations conferring resistance to the new NNRTIs (etravirine). Seven patients were resistant to AZT, d4T, 3TC, NVP, and EFV (6 in M24).

\section{Factors associated with virological failure}

Factors significantly associated with virological failure were longer time on therapy (OR 2.0; 95\% CI 1.2-3.6 for M24 compared with M12 patients), $\geq 35$ years of age at ART start (OR 0.5; 95\% CI 0.3-0.8), TB diagnosis during ART (OR 2.3; 95\% CI 1.0-5.0), weight less than baseline weight at time of ART initiation (OR 2.2; 95\% CI 1.3-
3.9), poor adherence (using VAS, OR 3.9; 95\% CI 1.97.7), low NNRTI plasma concentration (OR 2.4; 95\% CI 1.2-4.8), and presentation of general signs or symptoms (myalgia, hepatomegaly, splenomegaly, or lymphadenopathy; OR 2.6; 95\% CI 1.5-4.5) (Table 3).

\section{NNRTI plasma concentrations}

In the M12 cohort, plasmatic concentrations of NVP and EFV were low in $19.1 \%(39 / 204)$ and $4.3 \%(1 / 23)$ of patients, respectively, and high in $24.5 \%$ (50/204) and $39.1 \%(9 / 23)$, respectively. NFV plasmatic concentrations were within normal therapeutic ranges $(n=2)$. In the M24 cohort, low plasma NVP concentrations were observed in $12.4 \%(32 / 258)$ of patients and high NVP and EFV concentrations in $20.9 \%(54 / 258)$ and $38.9 \%(7 / 18)$, respectively.

Factors associated with low NNRTI plasma concentrations Overall, the proportion of patients with low ARV concentrations significantly increased with increasing HIV RNA levels (from $12.8 \%$ in patients with undetectable VL to $22.7 \%$ in those with virological failure, $P=0.02)$. This association was observed in both cohorts (Figure 2).

Poor adherence in the last 4 days (OR 3.8, 95\% CI 1.97.4) and reported digestive disorders (OR 1.7, 95\% CI 0.9-2.9) were significantly associated with the presence of low plasma NNRTI or NFV concentrations (Table 3), but these factors were unrelated to the weight of the patients (data not shown).

\section{Discussion}

In the HIV care and treatment program of Arua, in rural Uganda, more than $70 \%$ of the patients remained in care after 1 or 2 years of treatment, but over $35 \%$ of patients remained at risk of developing opportunistic infections $\left(<200\right.$ cells $\left./ \mathrm{mm}^{2}\right)$. Estimates of retention in care appear to be more favorable than those reported during the early years of the Drug Access Initiative (DAI) program among individuals treated in urban hospitals of Kampala, where patients were requested to pay the care fees $(49-56 \%$ at 1 
Table 3: Factors associated with virological failure and low plasma NNRTI concentrations

\begin{tabular}{|c|c|c|c|c|c|c|c|c|c|c|}
\hline & \multicolumn{5}{|c|}{ Virological failure } & \multicolumn{5}{|c|}{ Low NNRTI concentrations } \\
\hline & \multirow[t]{2}{*}{$n / \mathbf{N}$} & \multicolumn{2}{|c|}{ Univariate analysis } & \multicolumn{2}{|c|}{ Multivariate analysis $\dagger$} & \multirow[t]{2}{*}{$n / \mathbf{N}$} & \multicolumn{2}{|c|}{ Univariate analysis } & \multicolumn{2}{|c|}{ Multivariate analysis ${ }^{\dagger}$} \\
\hline & & OR (95\% Cl) & $P$ value & OR $(95 \% \mathrm{CI})$ & $P$ value & & OR (95\% Cl) & $P$ value & OR $(95 \% \mathrm{CI})$ & $P$ value \\
\hline $\begin{array}{l}\text { M24 cohort } \\
\text { (vs. MI2) }\end{array}$ & $50 / 506$ & $1.8(1.1-3.0)$ & 0.02 & $2.0(1.2-3.6)$ & 0.01 & $32 / 505$ & $0.6(0.4-1.0)$ & 0.06 & $0.7(0.4-1.1)$ & 0.15 \\
\hline \multicolumn{11}{|l|}{$\begin{array}{l}\text { Age at ART } \\
\text { start (vs. 15-34) }\end{array}$} \\
\hline$\geq 35$ years & $40 / 506$ & $0.5(0.3-0.9)$ & 0.02 & $0.5(0.3-0.8)$ & 0.01 & $46 / 505$ & I.I (0.7-I.9) & 0.58 & - & - \\
\hline \multicolumn{11}{|c|}{ School level (vs. secondary or higher) } \\
\hline $\begin{array}{l}\text { Primary or no } \\
\text { education }\end{array}$ & $47 / 506$ & $0.8(0.5-1.4)$ & 0.50 & - & - & $53 / 505$ & $1.5(0.9-2.6)$ & 0.14 & I.3 (0.8-2.4) & 0.3 \\
\hline \multicolumn{11}{|c|}{ Non-cumulative WHO stage at survey (vs. asymptomatic) } \\
\hline Stage $1-2$ & $32 / 490$ & $1.9(1.2-3.3)$ & 0.04 & $1.9(1.1-3.3)$ & 0.06 & & & & & \\
\hline Stage $3-4$ & $6 / 490$ & I.I (0.4-2.8) & & $0.8(0.3-2.2)$ & & - & - & - & - & - \\
\hline $\begin{array}{l}\text { TB episode after } \\
\text { ART }\end{array}$ & $11 / 506$ & $2.1(0.9-4.3)$ & 0.06 & $2.3(1.0-5.0)$ & 0.04 & - & - & - & - & - \\
\hline Weight $\leq$ baseline & $32 / 506$ & $1.9(1.2-3.3)$ & 0.009 & $2.2(1.3-3.9)$ & 0.004 & $15 / 505$ & $0.6(0.3-1.1)$ & 0.07 & $0.6(0.3-1.1)$ & 0.11 \\
\hline \multicolumn{11}{|l|}{$\begin{array}{l}\text { ARV-related } \\
\text { toxicity }\end{array}$} \\
\hline Digestive & $49 / 506$ & $1.6(0.9-2.8)$ & 0.05 & $1.5(0.8-2.6)$ & 0.15 & $48 / 505$ & $1.8(1.1-3.0)$ & 0.03 & $1.7(0.9-2.9)$ & 0.05 \\
\hline Dermatologic & $31 / 506$ & $1.8(1.1-2.9)$ & 0.03 & $1.6(0.9-2.8)$ & 0.08 & $21 / 505$ & $0.9(0.5-1.6)$ & 0.82 & - & - \\
\hline $\begin{array}{l}\text { General } \\
\text { symptoms* }\end{array}$ & $30 / 506$ & $2.3(1.4-3.9)$ & 0.002 & $2.6(1.5-4.5)$ & 0.001 & $17 / 505$ & $0.9(0.5-1.6)$ & 0.74 & - & - \\
\hline \multicolumn{11}{|c|}{ Poor adherence to ART (<95\% vs. $\geq 95 \%)$} \\
\hline $\begin{array}{l}\% \text { pills taken in } \\
\text { last } 4 d\end{array}$ & $11 / 506$ & $1.8(0.0-3.8)$ & 0.11 & I.I (0.4-2.6) & 0.85 & $17 / 505$ & $4.0(2.1-7.7)$ & 0.0001 & $3.8(1.9-7.4)$ & $<0.0001$ \\
\hline 30-day VAS & $19 / 506$ & $3.4(1.8-6.4)$ & 0.0002 & $3.9(1.9-7.7)$ & 0.0001 & - & - & - & - & - \\
\hline $\begin{array}{l}\text { Nadir } \text { CD4 }^{+}<50 \\
\text { cells } / \mathrm{mm}^{3} \text { (vs. } \geq \\
50)\end{array}$ & $24 / 506$ & $1.5(0.9-2.6)$ & 0.14 & I.5 (0.8-2.6) & 0.20 & $19 / 503$ & I.I (0.6-1.9) & 0.77 & - & - \\
\hline $\begin{array}{l}\text { Low NNRTI } \\
\text { plasma } \\
\text { concentration at } \\
\text { survey }\end{array}$ & $17 / 505$ & $1.9(1.1-3.7)$ & 0.03 & $2.4(1.2-4.8)$ & 0.01 & - & - & - & - & - \\
\hline
\end{tabular}

TB, tuberculosis; VAS, visual analogue scale; NNRTI, non-nucleoside reverse transcriptase inhibitor; OR, odds ratio; Cl, confidence interval. *General signs or symptoms: myalgia, hepatomegaly, splenomegaly, or lymphadenopathy; VAS.

tMultiple logistic regression using backward elimination approach and controlling for the effect of all variables for which adjusted estimates are shown.

year, and $46 \%$ at 2 years of ART) and more than $30 \%$ were ARV-experienced $[3,5]$. Like in other African settings, most of our patients started treatment at an advanced stage of HIV disease [4,10,22-24], which partly explains why a considerable proportion of patients had low CD4 cell counts after 1 or 2 years of therapy. As reported previously [11,25-27], early mortality in our cohorts was high with $88 \%$ of deaths occurring in the first 6 months of followup under ART. Delays in access to care $(>80 \%$ of patients started treatment at an advanced clinical stage of HIV disease), delayed diagnosis and treatment of severe opportunistic infections (e.g. TB), undiagnosed severe immune reconstitution inflammatory syndromes, and nutritional deficiencies might have contributed to this increased early mortality [28-31].

Despite the frequency of clinical intolerances reported, the initial ART regimen was well tolerated, and few cases 


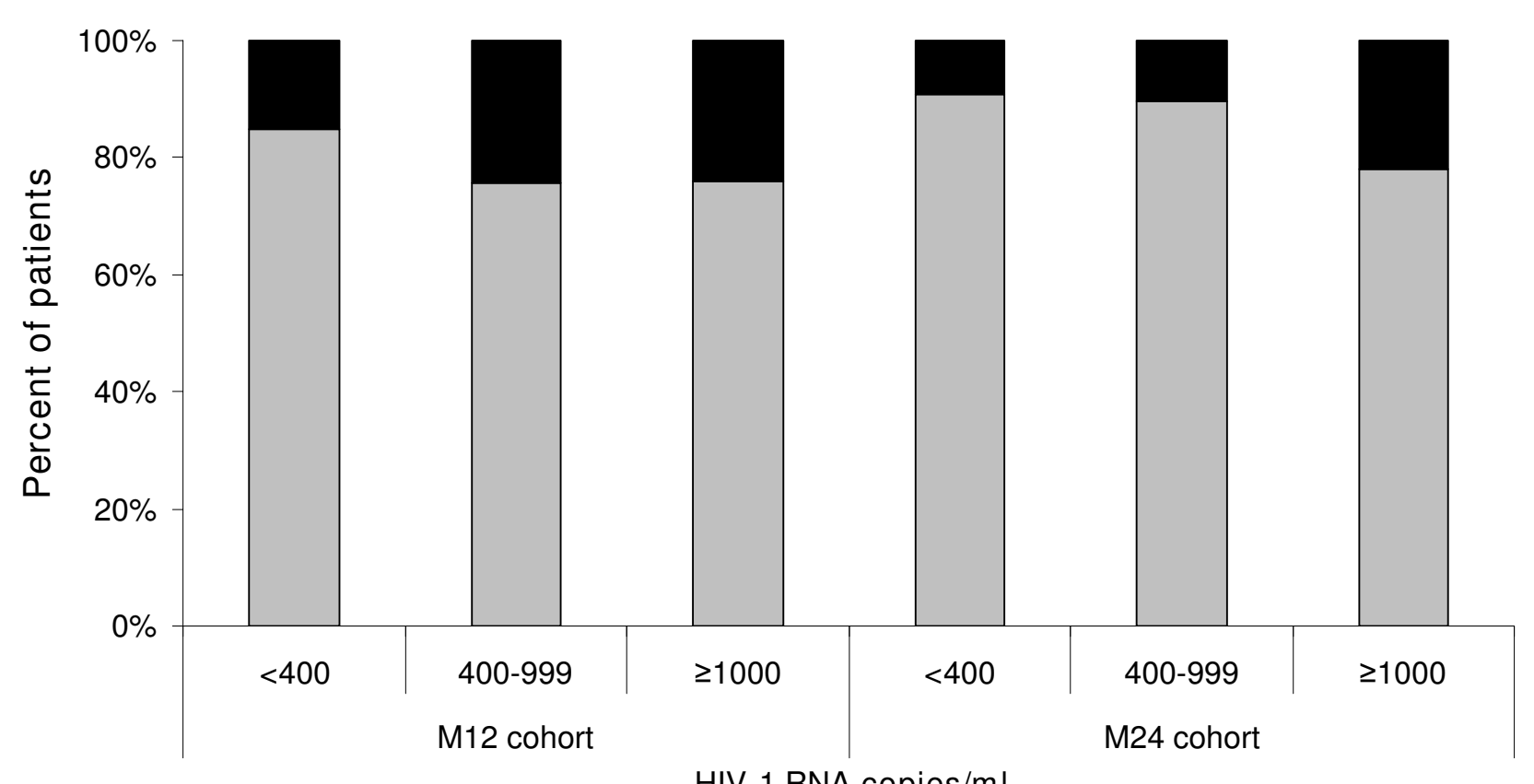

Normal/high ARV level $\quad$ Low ARV level

\section{Figure 2}

\section{HIV-I RNA values by ARV drug plasma level and by cohort.}

of severe (grades 3 or 4 ) laboratory-based toxicity were diagnosed. Self-reported adherence at 12 and 24 months of ART was high and similar to that reported in other studies, both in resource-limited countries [32] and North America [33,34], with a higher proportion of patients reporting good adherence in the M24 cohort than the M12 cohort ( $90 \%$ compared with $80 \%$, respectively). Although reported adherence is subject to measurement error and we cannot exclude that some patients overreported their level of adherence to ART during the survey, these findings were consistent with plasmatic ARV pharmacological measurements obtained in the same patients. However, the reported levels of adherence do not necessarily reflect patient's compliance throughout the duration of treatment.

The observed immune and virological responses at 1 and 2 years of ART were similar to those reported in other African settings $[4,10,11,22,35,36]$ and in Western countries [37]. However, more than 35\% of patients had a CD4 count $<200$ cells $/ \mathrm{ml}$ and were therefore at increased risk of death due to occurrence of opportunistic diseases. In the M12 cohort, undetectable VL was achieved by 75\% of the patients, and $89 \%$ had a VL $<1,000$ copies/ml. In Malawi, $87 \%$ of the patients receiving a 2 NRTI/1 NNRTI-based regimen had a $\mathrm{VL}<1,000$ copies/ml after a median of 10 months [10]. The DART study conducted in Zimbabwe and Uganda reported that $72 \%$ of patients who received AZT/3TC/TDF for a year had undetectable VL [4]. Also, in a teaching hospital of Kampala, undetectable VL was observed in $86 \%$ of patients treated with $\mathrm{d} 4 \mathrm{~T} / 3 \mathrm{TC} / \mathrm{NVP}$ for 1 year [7]. Similarly, in a patient cohort in Khayelitsha, South Africa, $70 \%$ of patients achieved undetectable VL at 1 year of ART [11]. In our M24 cohort, undetectable VL was achieved by $71 \%$ of the patients. Lower virological success rates have been reported in four urban clinics in Senegal, Côte d'Ivoire, Uganda, and Kenya after 2 years of ART (40-69\% had a VL <400 copies/ml) [36].

Overall, $7 \%$ of patients with virological failure at M12 and $13 \%$ at M24 had resistant virus, which is similar to estimates reported for patients treated with 2 NRTI/1 NNRTIbased therapy in east Africa or South-east Asia after more than 9 months of treatment $(9-18 \%)[10,35,38]$. This figure might be underestimated if patients with unsuppressed HIV VL (400-999 copies/ml) but not virological failure also had viral mutations conferring resistance to therapy. More conservative estimates of prevalence of resistance would therefore be $18 \%$ and $21 \%$ of M12 and M24 patients, respectively, on treatment. 
Estimates of resistance and virological and immunological failure might also have been underestimated if some of the deaths or patients who were lost to follow-up died as a result of treatment failure and resistance. However, most deaths and losses to follow-up occurred within the first months of therapy when the likelihood of treatment failure was lower. Conversely, because our study is based on outcome data collected at a single time point and no confirmation of laboratory data was obtained in the following weeks, we might have slightly overestimated rates of virological and immunological failure due to measurement errors or to individual temporal variability in biological markers (e.g. HIV viral blips). As in previous studies conducted in patients using primarily d4T/3TC/ $\mathrm{NVP}$, the most commonly observed resistance mutations were those associated with the use of NNRTIs (K103N) and 3TC $(\mathrm{M} 184 \mathrm{~V})[7,10,38]$, and none of the isolated viruses had mutations conferring resistance to the new NNRTIs (etravirine).

Patients on ART for 2 years were twice as likely as those on 1 year treatment to develop virological failure. Patients diagnosed with TB after ART initiation were also more likely to fail therapy, suggesting that patients' virological response could be impaired when rifampicin-based antiTB treatment is initiated while a patient is under ART. The potential interaction between NVP and rifampicin in HIVinfected patients treated for TB has been reported in previous studies [39-43]. This can result in subtherapeutic NVP plasma concentrations [39] and favor the development of resistance to this drug. Alternatively, pill burden associated with concomitant treatments could lead to decreased adherence to one or both regimens.

Early identification of patients with virological failure and switch to second-line therapy is important to prevent the accumulation of resistance that might compromise the effectiveness of subsequent lines of treatment. In this program where virological monitoring of patients is not routinely performed, patients presenting general clinical symptoms, those with a weight loss below the value observed at therapy initiation, or those reporting poor adherence were more likely to have virological failure. The association between high VL levels and subtherapeutic NNRTI concentrations has been previously reported in Malawi [44] and Cambodia [38], highlighting the importance of maintaining and reinforcing patients' adherence over time. In our study, patients severely immunosuppressed at the time of the survey were not more likely to have virological failure, although this might change if patients remain in a failing regimen for longer periods of time [38].

The pharmacological assessment showed increased plasmatic levels of NNRTI in 23\% of patients on NVP-based therapy and 39\% of those on EFV. These figures are higher than what has been described in Western countries, and are likely to be related to the lower weight of our patients at ART initiation [44] compared with European patients $[45,46]$. In contrast, subtherapeutic levels of NVP and EFV were found in $15 \%$ and $2 \%$ of the patients, respectively. As in previous studies, the risk of having low NNRTI concentrations in plasma was nearly 4 times higher in patients with poor self-reported adherence $[44,47]$. We also found a higher risk of subtherapeutic ARV levels in patients who reported digestive disorders at the time of the survey. Vomiting, malabsorption, or misclassification bias (e.g. if patients who reported symptoms were also more likely to report poor adherence) could contribute to explain this finding.

\section{Conclusion}

In conclusion, in this HIV/AIDS care program implemented in a rural African setting using a simplified scaleup approach and free generic ART, survival and retention in care were satisfactory at up to 2 years of therapy, but efforts to increase earlier access to treatment and to improve patient management and support to achieve better immunological and virological outcomes on ART remain necessary to prolong patient survival. Early identification of poor adherence during follow-up, especially in the presence of intolerance to ARV and when TB treatment is provided, should be considered to maximize the duration of first-line therapy.

\section{Competing interests}

The authors declare that they have no competing interests.

\section{Authors' contributions}

LA designed and implemented the study, analyzed and managed data, interpreted results, and wrote the manuscript. GG and CO set up and implemented the study in the field and contributed to the interpretations of results. LP performed statistical analyses. PA contributed to the design, set-up, and implementation of the study. M-LC and CLT performed the virological and pharmacological tests and contributed to the interpretation of the results. $\mathrm{SB}$ and DO helped to design the study, interpret the results, and draft the manuscript. MP-R performed statistical analysis, interpreted results, and co-wrote the manuscript. All authors read and approved the final manuscript.

\section{Acknowledgements}

The authors would like to thank the patients and their families for their participation in the study and for their motivation and collaboration. We also thank the medical personnel of the Ugandan Ministry of Health and the MSF field team for their support and technical advice in the implementation of this study. Thanks to Oliver Yun for his editorial support. Financial support for this study was provided by Médecins Sans Frontières. 


\section{References}

I. UNAIDS: Epidemiological fact sheets on HIVIAIDS and STIs. Uganda; 2008 update. [http://www.unaids.org/en/ Regions Countries/Countries/Uganda.asp].

2. Kebba A, Atwine D, Mwebaze R, Kityo C, Nakityo R, Peter M: Therapeutic responses to AZT + 3TC + EFV in advanced antiretroviral naive HIV type I-infected Ugandan patients. AIDS Res Hum Retroviruses 2002, 18:1/8I-II87.

3. Weidle PJ, Malamba S, Mwebaze R, et al.: Assessment of a pilot antiretroviral drug therapy programme in Uganda: patients' response, survival, and drug resistance. Lancet 2002, 360:34-40

4. DART Virology Group and Trial Team: Virological response to a triple nucleoside/nucleotide analogue regimen over 48 weeks in HIV-I-infected adults in Africa. AIDS 2006, 20:139|-I399.

5. Kabugo C, Bahendeka S, Mwebaze R, et al.: Long-term experience providing antiretroviral drugs in a fee-for-service HIV clinic in Uganda: evidence of extended virologic and CD4+ cell count responses. J Acquir Immune Defic Syndr 2005, 38:578-583.

6. Spacek LA, Shihab HM, Kamya MR, et al.: Response to antiretroviral therapy in HIV-infected patients attending a public, urban clinic in Kampala, Uganda. Clin Infect Dis 2006, 42:252-259.

7. Kamya MR, Mayanja-Kizza H, Kambugu A, et al.: Predictors of longterm viral failure among Ugandan children and adults treated with antiretroviral therapy. I Acquir Immune Defic Syndr 2007, 46: 187-193.

8. Gilks CF, Crowley S, Ekpini R, et al.: The WHO public-health approach to antiretroviral treatment against HIV in resource-limited settings. Lancet 2006, 368:505-5I0.

9. World Health Organization: Scaling up access to antiretroviral therapy in Resource-limited settings: treatment guidelines for a public health approach. 2003 revision. Geneva: WHO; 2004.

10. Ferradini L, Jeannin A, Pinoges L, et al.: Scaling up of highly active antiretroviral therapy in a rural district of Malawi: an effectiveness assessment. Lancet 2006, 367:1335-1342.

II. Coetzee D, Hildebrand K, Boulle A, et al: Outcomes after two years of providing antiretroviral treatment in Khayelitsha, South Africa. AIDS 2004, I 8:887-895.

12. Wu EY, Wilkinson JM, Naret DG, et al:: High-performance liquid chromatographic method for the determination of nelfinavir, a novel HIV-I protease inhibitor, in human plasma. Chromatogr B Biomed Sci Appl 1997, 695:373-380.

13. van Heeswijk RP, Hoetelmans RM, Meenhorst PL, Mulder JW, Beijnen $\mathrm{JH}$ : Rapid determination of nevirapine in human plasma by ion-pair reversed-phase high-performance liquid chromatography with ultraviolet detection. J Chromatogr B Biomed Sci Appl 1998, 71 3:395-399.

14. Rouet F: Transfer and evaluation of an automated, low-cost real-time reverse transcription-PCR test for diagnosis and monitoring of human immunodeficiency virus type $I$ infection in a West African resource-limited setting. J Clin Microbiol 2005, 43:2709-27I7.

15. Descamps D: French national sentinel survey of antiretroviral drug resistance in patients with HIV-I primary infection and in antiretroviral-naïve chronically infected patients in $200 \mathrm{I}-$ 2002. J Acquir Immune Defic Syndr 2005, 38:545-552.

16. ANRS: The French ANRS (National Agency for AIDS Research) ACII HIV-I Resistance Group: HIV-I genotypic drug resistance interpretation algorithms. [http://www.hiv frenchresistance.org].

17. AIDS Clinical Trial Group: Division of AIDS table for grading the severity of adult and pediatric adverse events. 2004 [http:// www.aactg.org/]

18. World Health Organization: Antiretroviral therapy for HIV infection in adults and adolescents: recommendations for a public health approach. Geneva: WHO; 2006.

19. World Health Organization: WHO consultation on ART failure in the context of public health approach. Draft meeting report. Geneva: WHO; 2008.

20. Taburet AM, Garrafo R, Goujard C, Molina M, Peytavin G, Treluyer JM: [Pharmacologie des Antirétroviraux: Indications des dosages plasmatiques des antirétroviraux]. In Prise en charge médicale des personnes infectées par le VIH. Rapport 2006, Recommandations du groupe d'experts Sous la direction du Professeur Patrick Yeni Edited by: Flammarion SA, Direction Générale de la Sante ANRS. Paris: République Française. Ministère de la Santé et des solidarités; 2006: 17I-184.

21. Bouyer J, Hémon D, Cordier S, et al.: Epidemiologie, principes et méthodes quantitatives. INSERM ed. Paris; 1995.

22. Djomand G, Roels T, Ellerbrock T, et al.: Virologic and immunologic outcomes and programmatic challenges of an antiretroviral treatment pilot project in Abidjan, Cote d'Ivoire. AIDS 2003, I7(Suppl 3):S5-SI5.

23. Libamba E, Makombe S, Mhango E, et al.: Supervision, monitoring and evaluation of nationwide scale-up of antiretroviral therapy in Malawi. Bull World Health Organ 2006, 84:320-326.

24. Stringer JS, Zulu I, Levy J, et al.: Rapid scale-up of antiretroviral therapy at primary care sites in Zambia: feasibility and early outcomes. JAMA 2006, 296:782-793.

25. Braitstein P, Brinkhof MW, Dabis F, et al.: Mortality of HIV-Iinfected patients in the first year of antiretroviral therapy: comparison between low-income and high-income countries. Lancet 2006, 367:817-824.

26. Etard JF, Ndiaye I, Thierry-Mieg M, et al.: Mortality and causes of death in adults receiving highly active antiretroviral therapy in Senegal: a 7-year cohort study. AIDS 2006, 20:1 I8I-I I89.

27. Zachariah R, Fitzgerald M, Massaquoi M, et al.: Risk factors for high early mortality in patients on antiretroviral treatment in a rural district of Malawi. AIDS 2006, 20:2355-2360.

28. Anabwani G, Navario P: Nutrition and HIVIAIDS in sub-Saharan Africa: an overview. Nutrition 2005, 21 1:96-99.

29. Badri M, Lawn SD, Wood R: Short-term risk of AIDS or death in people infected with HIV-I before antiretroviral therapy in South Africa: a longitudinal study. Lancet 2006, 368:1254-1259.

30. DeSimone JA, Pomerantz RJ, Babinchak TJ: Inflammatory reactions in HIV-I-infected persons after initiation of highly active antiretroviral therapy. Ann Intern Med 2000, I33:447-454.

31. Gandhi NR, Moll A, Sturm AW, et al.: Extensively drug-resistant tuberculosis as a cause of death in patients co-infected with tuberculosis and HIV in a rural area of South Africa. Lancet 2006, 368: I575-I580

32. Weidle PJ, Wamai N, Solberg P, et al.: Adherence to antiretroviral therapy in a home-based AIDS care programme in rural Uganda. Lancet 2006, 368: I587-1594.

33. Diamond C, Richardson JL, Milam J, et al.: Use of and adherence to antiretroviral therapy is associated with decreased sexual risk behavior in HIV clinic patients. J Acquir Immune Defic Syndr 2005, 39:211-218.

34. Russell J, Krantz S, Neville S: The patient-provider relationship and adherence to highly active antiretroviral therapy. I Assoc Nurses AIDS Care 2004, I 5:40-47.

35. Laurent C, Ngom Gueye NF, Ndour CT, et al.: Long-term benefits of highly active antiretroviral therapy in senegalese HIV-Iinfected adults. J Acquir Immune Defic Syndr 2005, 38: I4-I7.

36. Sow PS, Otieno LF, Bissagnene E, et al.: Implementation of an antiretroviral access program for HIV-I-infected individuals in resource-limited settings: clinical results from 4 African countries. J Acquir Immune Defic Syndr 2007, 44:262-267.

37. Bartlett JA, DeMasi R, Quinn J, Moxham C, Rousseau F: Overview of the effectiveness of triple combination therapy in antiretroviral-naive HIV-I infected adults. AIDS 200I, 15:1369-1377.

38. Ferradini L, Laureillard D, Prak N, et al.: Positive outcomes of HAART at 24 months in HIV-infected patients in Cambodia. AIDS 2007, 2I:2293-230I.

39. Cohen K, Van CG, Boulle A, et al.: Effect of rifampicin-based antitubercular therapy on nevirapine plasma concentrations in South African adults with HIV-associated tuberculosis. Antimicrob Chemother 2008, 61:389-393.

40. Autar RS, Wit FW, Sankote J, et al.: Nevirapine plasma concentrations and concomitant use of rifampin in patients coinfected with HIV-I and tuberculosis. Antivir Ther 2005, 10:937-943.

4I. Ribera E, Pou L, Lopez RM, et al.: Pharmacokinetic interaction between nevirapine and rifampicin in HIV-infected patients with tuberculosis. J Acquir Immune Defic Syndr 200I, 28:450-453.

42. Dean GL, Back DJ, de RA: Effect of tuberculosis therapy on nevirapine trough plasma concentrations. AIDS 1999, 13:2489-2490. 
43. Boulle A, Van CG, Cohen K, et al.: Outcomes of nevirapine- and efavirenz-based antiretroviral therapy when coadministered with rifampicin-based antitubercular therapy. JAMA 2008, 300:530-539.

44. van Oosterhout JJ, Bodasing N, Kumwenda JJ, et al.: Evaluation of antiretroviral therapy results in a resource-poor setting in Blantyre, Malawi. Trop Med Int Health 2005, 10:464-470.

45. Donnerer J, Kronawetter M, Kapper A, Haas I, Kessler HH: Therapeutic drug monitoring of the HIVIAIDS drugs abacavir, zidovudine, efavirenz, nevirapine, indinavir, lopinavir, and nelfinavir. Pharmacology 2003, 69:197-204.

46. Zhou XJ, Sheiner LB, D'Aquila RT, et al.: Population pharmacokinetics of nevirapine, zidovudine, and didanosine in human immunodeficiency virus-infected patients. Antimicrob Agents Chemother 1999, 43:121-128.

47. Mills EJ, Nachega JB, Buchan I, et al.: Adherence to antiretroviral therapy in sub-Saharan Africa and North America: a metaanalysis. JAMA 2006, 296:679-690.

\section{Pre-publication history}

The pre-publication history for this paper can be accessed here:

http://www.biomedcentral.com/1471-2334/9/81/prepub

Publish with Bio Med Central and every scientist can read your work free of charge

"BioMed Central will be the most significant development for disseminating the results of biomedical research in our lifetime. "

Sir Paul Nurse, Cancer Research UK

Your research papers will be:

- available free of charge to the entire biomedical community

- peer reviewed and published immediately upon acceptance

- cited in PubMed and archived on PubMed Central

- yours - you keep the copyright

Submit your manuscript here:

http://www.biomedcentral.com/info/publishing_adv.asp 